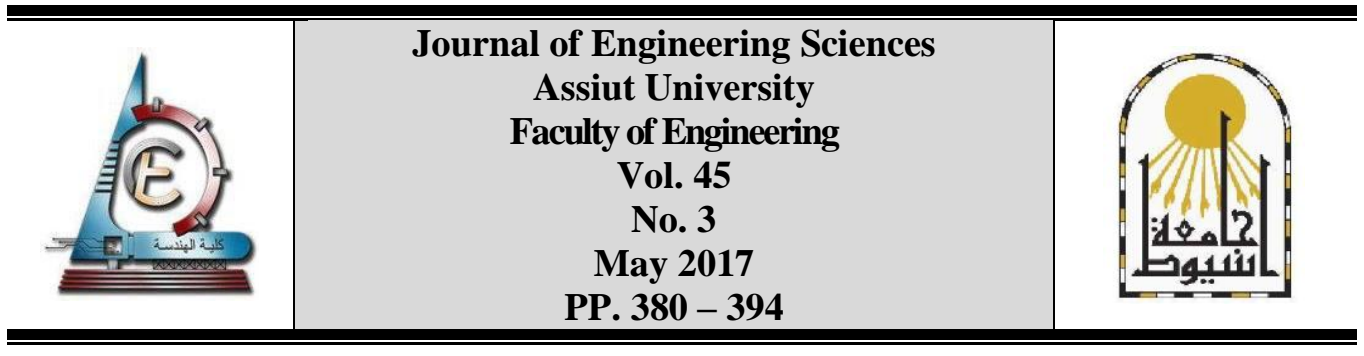

\title{
ENHANCING THE PERFORMANCE OF DAYLIGHTING IN TOPLIT DRAWING HALLS USING DIVA-FOR-RHINO AS ONE OF THE SIMULATION PROGRAMS: \\ "A CASE STUDY OF DRAWING HALLS IN CAIRO, EGYPT AS A HOT ARID CLIMATE"
}

\author{
Ashraf Ali Ibrahim Nessim \\ Architectural Engineering Department, Faculty of Engineering, Ain Shams University.
}

Received 4 January 2017; Accepted 25 February 2017

\begin{abstract}
Several studies showed the clear relationship between the human performance inside buildings and the presence of appropriate daylight. As well known, daylighting promotes health and vitality which had been scientifically proven to improve the academic performance of students in educational buildings due to long hours spent within such spaces during the daytime. In addition to reducing or eliminating electric lighting during daytime, daylighting helps in creating a visual stimulating and productive environment for occupants.

This paper aims at enhancing daylighting performance in case of existing toplit educational spaces. Daylighting simulations were conducted on a north-east oriented toplit drawing hall, located in the city of Cairo, Egypt. A plug-in used to interface Radiance and Daysim, namely Diva-forRhino, was used to calculate and analyze the daylight performance within the drawing hall. Divafor-Rhino is considered a highly optimized daylighting plug-in for the Rhinoceros and allows users to carry out a series of environmental performance evaluations. Several techniques were examined to enhance the daylight performance but the research focuses on the use of louvers as solar screens to control daylighting and the associated glare. Louvers when compared to other techniques have the advantage of being easily retrofitted and installed. Two different positions for the louvers were proposed and simulations were carried-out.
\end{abstract}

Results showed that the Daylight Availability (DA) could be significantly enhanced using additional and retrofitted techniques by reducing the "Overlit" zone from $100 \%$ to almost $50 \%$ and keeping the ASE within the favorable limit (less than 10\%).

Keywords: Clear Sky, Daylighting Performance, Toplighting, Drawing Halls, Solar Screen, Daylight Availability (DA), Daylight Glare Probability (DGP), Spatial Daylight Autonomy (sDA), Annual Sunlight Exposure (ASE)

\section{Introduction}

Daylighting is considered essential in educational spaces as it affects performance, mood and attention of users. New educational buildings reflect new philosophies of education and new technologies for instruction. The main goal of daylighting educational 
spaces is to provide an appropriate visual environment for both students and tutors which becomes supportive of the learning processes. This can be achieved only if the occupants can see their visual tasks accurately, quickly, and comfortably [9]. Accordingly, the use of light in educational spaces should be both functional and inspirational. From the function point of view, the light should allow the students to focus on their task. As for inspiration, the lighting should be consistent with the psychological and emotional needs of the students. Many existing educational spaces need retrofitting to improve the lighting performance and the visual environment.

The researcher reviewed the available drawing halls in several universities in Cairo, Egypt. It was found that in some cases the designer used toplighting techniques to enhance the daylighting performance. Unfortunately, the site limitations, structure system, orientation and other factors influenced the performance of the used toplighting technique which led to the dissatisfaction of the users in specific timing throughout the day.

\section{Regarding the glare problems, the following researches were examined:}

Al-Sallal (2007) investigated the use of reflective light shelf to reduce glare problems and redistribute daylight resulting from the use of toplighting in design studios in U.A.E. as a hot desert climate. Several design parameters were studied including the slope of the roof and the height and slope of the light shelf. It was found that sloped roof performed better than the horizontal roof and improved the performance of the light shelf [3].

Another paper by Bellia et al. (2008) compared the daylight glare index (DGI) with the results of the perceived daylight discomfort glare. The aim of the study was to define limits and applicability of DGI and to note and define possible changes. The results indicated that the DGI in many cases provides discomfort glare values that are noticeably greater than those perceived in real situations [4].

A paper by Alrubaih et al. (2013) reviewed the fundamental aspects of daylighting and its design strategies, including the daylight factor, illuminance and luminance, and glare index. The paper studied the impact of the illuminance level and its distribution on the work plane and the surrounding area and it concluded that the illuminance level and its distribution have a great impact on how quickly, safely, and comfortably an occupant perceives and carries out a visual task [2].

\section{Regarding the available techniques used to enhance the daylighting performance within the space, the following researches were examined:}

A paper by Abdelatia et al. (2010) proposed and tested several architectural devices that can be integrated into educational building designs, allowing the penetration of natural daylight while respecting the traditional architecture and creating a comfortable school environment in Libya as a hot arid climate. The study applied sustainable architectural design strategies to utilize natural daylight by spreading out of natural daylight, protecting the apertures against solar radiation or glaring light, and controlling of the natural daylight [1].

A paper by Sabry et al. (2012) examined the effect of the screen axial rotation and its opening proportion ratio on the year round daylight performance, and the resultant glare phenomena probability in hot arid climate. The findings prove that the solar screens can drastically improve the daylight distribution in rooms and spaces. When properly planned solar screens were employed, daylit areas reached $60 \%$ to $72 \%$ of the spaces. Meanwhile, the glare phenomenon was eliminated in the East, West and South orientations [12]. 
Another paper by Sabry et al. (2012) addressed the usefulness of combing solar screens and light shelves for achievement of efficient daylight performance in a residential living room space in clear sky desert buildings in hot arid climate. The impact of combined design alternatives and techniques was tested for the purpose of increasing the daylit and reducing the over-lit and partially-daylit areas. The results showed significant improvements in daylight distribution in all orientations. In the North and South orientations, more than one combined design attained the highest value for daylit area, reaching $95 \%$ and $85 \%$ in these orientations respectively. While in the East orientation, only one combination achieved this goal where a 67\% "daylit" area was reached [13].

A paper by Sherif et al. (2016) examined the different shapes of horizontal blind slats that best suit a common hospital patient room under the clear-sky of Cairo, Egypt as a hot arid climate. Results shown that all tested slat shapes provided acceptable ASE performance. Blinds with flat or gently curved slat shapes lead to better results in both daylighting and external view exposure. Position of the intermediate point of the slat fell in a narrow vertical range around the horizontal base line and that changing the position of the intermediate point horizontally in either direction resulted in a marginal effect on the performance of the accepted cases [14].

A paper by Skarning et al. (2017), examined the effect of dynamic solar shading on several aspects, including daylighting by comparing two cases one located in a hot climate and the other in a cold climate. The paper showed that dynamic shading can multiply daylighting by 750-1000h more than could be achieved without shading in hot climate [15].

In order to examine the effect of daylight on the occupants, a paper by Laura et al. (2013) was reviewed. The researchers analyzed the effect of daylight and electric light in educational environments, in Mediterranean climate, by examining the spectral power distribution (SPD), the spectral characteristics, and the Correlated Color Temperature (CCT) of light. The results showed that all the previously mentioned have a significant role on the human circadian response and accordingly affecting the users' performance [5].

\section{Regarding the daylighting simulation programs used in previous researches, the following can be deduced from the previously examined researches:}

In recent researches by Sabry et al. (2012) (2 papers) and Sherif et al. (2016), Diva-forRhino was used in the simulation process. Skarning et al. (2017) used EnergyPlus with the tool jEPlus. Another paper by Kim et al. (2011) used Radiance in the simulation process.

Consequently, the previous papers focused on the performance of the daylighting in educational spaces and its impact on the occupants' performance. In addition, other papers focused on the use of solar screens to achieve efficient daylight. As a result of the above review, it is clear that several techniques can be used to enhance the daylight performance in hot arid climate and limit glare but the research shall focus on the use of louvers as solar screens to control daylighting and the associated glare. Louvers when compared to other techniques have the advantage of being easily retrofitted and installed [7]. Two different locations for the louvers, interior and exterior, were proposed to enhance the daylighting performance of the toplighting technique used in the drawing hall. In addition, most recent simulations were carried out using Diva-for-Rhino, a plug-in for Rhinoceros modeling software, to evaluate the proposed techniques. Accordingly, the same simulation package was used and the results were analyzed and discussed below. 


\section{Objectives}

The objective of this paper is to examine how to enhance the daylighting performance in case of an existing toplit educational space located in Cairo, Egypt as a hot arid climate. After examining the sun path diagram for the location of the drawing hall and the shading mask for months that users reported glare discomfort in the space (May, June and July), the initial design for the louvers showed the possible use of horizontal louvers $50 \mathrm{~cm}$ wide with a vertical spacing that block the direct sunlight at 45 degrees. Accordingly, the paper examines the effect of adding external horizontal shading devices with the aforementioned dimensions and spacing. Another proposed solution was to use internal vertical shading devices with the same dimensions and spacing in order to compare which position provides a better performance. The paper compares the result of both proposals regarding the daylight performance and the resultant glare phenomena probability.

\section{Research problem}

The amount of daylight available within spaces affects the performance of the users drastically. "Overlit" spaces can cause serious visual problems that need to be addressed. "Overlit" spaces can result from the poor design of fenestrations. In addition, glare significantly affects the performance of the users as it affects negatively the functioning of the space.

\section{Research hypothesis}

The daylighting performance in case of an existing toplit educational space can be affected dramatically and enhanced using retrofitted shading devices or other solar shading techniques. In addition, glare phenomena can be overcome using shading devices. Moreover, computational methods along with simulation tools can be used to predict the performance of the proposed solution to select the optimum proposed technique to be used.

\section{Methodology}

An existing drawing hall was selected for assessment. The selection was based on the fact that several students reported visual discomfort during the utilization period as a result of the sun angles and the toplighting technique used. Simulations using the climatic data of the city of Cairo, Egypt $\left(30.0500^{\circ} \mathrm{N}, 31.2333^{\circ} \mathrm{E}\right)$ were conducted. Cairo is characterized by its hot arid climate and enjoys a clear sky most of the year.

The existing situation is referred to as the "Base Case" in this paper. All space measurements (length, width and height) were taken from the site. Figure (1) and Figure (2) shows the current conditions of the drawing hall where as Figure (3) and Table (1) illustrates the architectural parameters of the base case. Material reflectance and glazing transmittance were measured using a Luxmeter (model: Lutron LX-102).

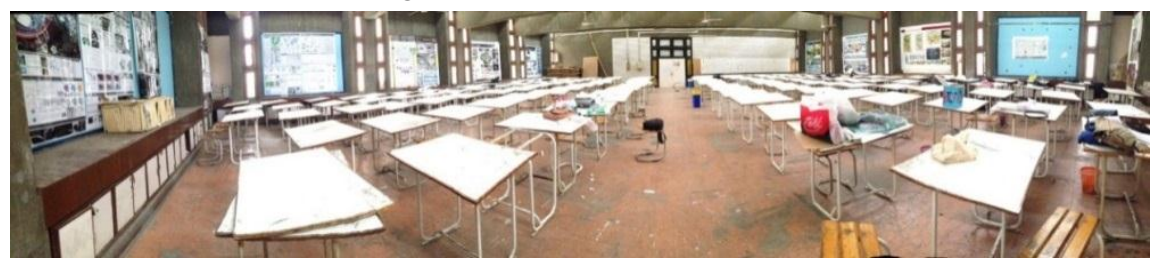

Fig. 1. Panoramic view of the drawing hall [Researcher]. 


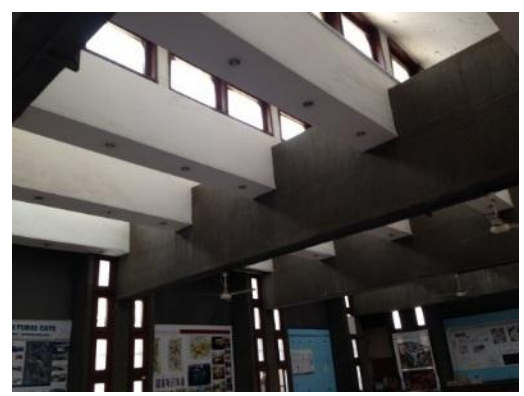

Fig. 2. View of the toplighting technique [Researcher].

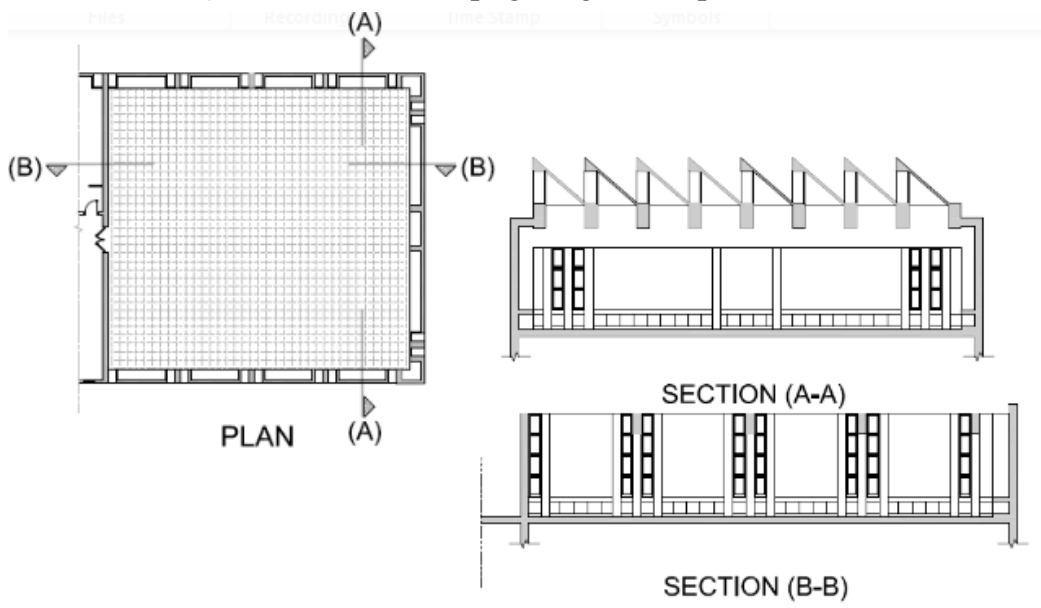

Fig. 3. Plan and sections showing the architectural Parameters of the "Base Case" [Researcher].

In addition to the sawtooth toplighting techniques, the drawing hall is illuminated using vertical strip windows $(60 \mathrm{cms}$ wide) that run from $100 \mathrm{~cm}$ above finish floor to the ceiling. This sidelighting is repeated every 5.40 meters on both sides and at the back of the hall as shown in Figure (4). The vertical windows have three orientations: East, West and South. The toplighting is used to enhance the daylighting penetration to the depth of the hall that extends to around 22.25meters length and spans around 20.60 meters in width as shown in Figure (5). The toplighting is north-east oriented.

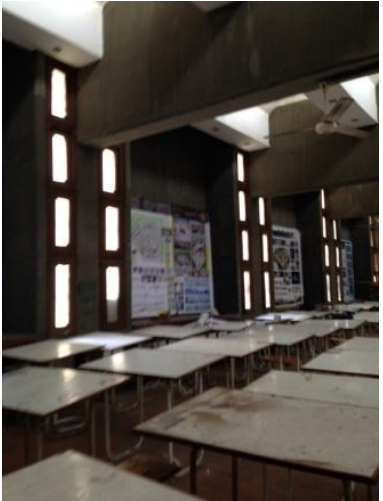

Fig. 4. Sidelighting penings (above left) [Researcher]

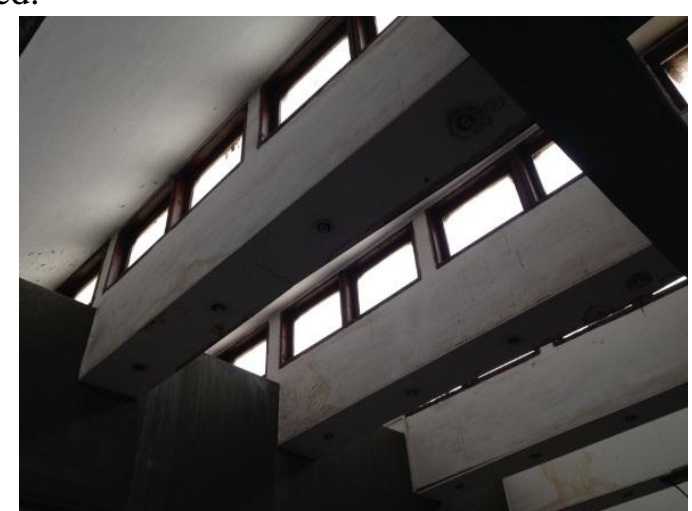

Fig. 5. Sawtooth toplighting technique that is used to enhance daylighting deep into the space (above right) [Researcher]. 
Table. 1.

Dimensions and parameters of the "Base Case".

\begin{tabular}{|c|c|c|c|c|}
\hline \multicolumn{5}{|c|}{ Drawing Hall Parameters } \\
\hline \multicolumn{2}{|c|}{ Floor Level } & \multicolumn{3}{|c|}{$4^{\text {th }}$ Floor $/+18.00 \mathrm{~m}$ from zero level } \\
\hline \multicolumn{2}{|c|}{ Dimensions } & \multicolumn{3}{|c|}{$22.25 \mathrm{~m}(\mathrm{~L}) \times 20.60 \mathrm{~m}(\mathrm{~W}) \times 5.00 \mathrm{~m}(\mathrm{H})$} \\
\hline \multicolumn{5}{|c|}{ Internal Surfaces } \\
\hline \multicolumn{5}{|c|}{$\begin{array}{l}\text { - Grey walls } 24.5 \% \\
\text { - White Walls } 79.5 \% \\
\end{array}$} \\
\hline Walls & Material & \multicolumn{3}{|c|}{$\begin{array}{l}\text { - East, south and west walls are medium grey colored. } \\
\text { - Part of the north wall is white colored. } \\
\text { - Wall panels are used as project display areas. }\end{array}$} \\
\hline \multirow{2}{*}{ Ceiling } & Reflectance & \multicolumn{3}{|c|}{$\begin{array}{l}\text { - Grey walls } 24.5 \% \\
\text { - White Walls } 79.5 \%\end{array}$} \\
\hline & Material & \multicolumn{3}{|c|}{$\begin{array}{l}\text { - Main frames are grey colored. } \\
\text { - Sawtooh ceiling is white colored. }\end{array}$} \\
\hline \multirow{2}{*}{ Floor } & Reflectance & \multicolumn{3}{|c|}{ - Dark orange17\% } \\
\hline & Material & \multicolumn{3}{|c|}{ - Vinyl Tiles $40 \mathrm{~cm}$ x $40 \mathrm{~cm}$} \\
\hline \multicolumn{5}{|c|}{$\begin{array}{l}\text { Sidelighting Parameters } \\
\end{array}$} \\
\hline & & \multicolumn{3}{|c|}{ Orientation } \\
\hline & & North & East / West & South \\
\hline \multirow{3}{*}{ Dimensions } & Width & - & $0.60 \mathrm{~m}$ & $0.60 \mathrm{~m}$ \\
\hline & Sill & - & $1.00 \mathrm{~m}$ & $1.00 \mathrm{~m}$ \\
\hline & Lintel & - & $5.00 \mathrm{~m}$ & $5.00 \mathrm{~m}$ \\
\hline \multicolumn{2}{|c|}{ Glazing Transmittance } & \multicolumn{3}{|c|}{$77.5 \%$} \\
\hline \multicolumn{5}{|c|}{ Sawtooth Parameters } \\
\hline \multirow{3}{*}{ Dimensions } & Height & \multicolumn{3}{|c|}{$1.55 \mathrm{~m}$} \\
\hline & Width & \multicolumn{3}{|c|}{$22.25 \mathrm{~m}$} \\
\hline & Spacing & \multicolumn{3}{|c|}{$2.50 \mathrm{~m}$} \\
\hline \multicolumn{2}{|c|}{ Glazing Transmittance } & \multicolumn{3}{|c|}{$77.5 \%$} \\
\hline
\end{tabular}

Diva-for-Rhino (version 4.0), a plug-in for Rhinoceros modeling software (Rhino 5), was used in the simulation process. Among other specialized simulation programs (Radiance, DAYSIM, Evalglare, VELUX Daylight Visualizer, DIAL+, etc....) [16], Divafor-Rhino is considered a highly optimized daylighting and energy modeling plug-in for the Rhinoceros. Diva-for-Rhino allows users to carry out a series of environmental performance evaluations including: Radiation Maps, Photorealistic Renderings, ClimateBased Daylighting Metrics, Annual and Individual Time Step Glare Analysis, LEED and CHPS Daylighting Compliance, and Single Thermal Zone Energy and Load Calculations. Among its advantages is its direct Rhino translation, simple output tools, the range of environmental analysis, quick result viewing and glare analysis [6].

\section{Daylighting performance metrics}

According to Reinhart et al. (2006), daylighting performance metrics are defined as "quality measures of day-lit building which help in assessing the behavior of daylighting inside the space and also establishing analytical comparative study by comparing the different measures". Daylighting performance metrics can be divided into two types: The static daylight performance metrics such as the daylight factor and the dynamic daylight performance metrics which consider the quantity and character of daily and seasonal variations of daylight for a given building site as an alternative to the daylight factor-based approaches [17]. 
This research focused on the Illuminating Engineering Society (IES) approved method for daylight metrics, which are Spatial Daylight Autonomy (sDA) and Annual Sunlight Exposure (ASE). Both metrics use the same building information and simulation methodology to analyze the hourly illumination patterns summed for an annual period across an analysis area [IES-The Daylight Metrics Committee, (2012)]. Another quantitative metric was used which is the Daylight Availability (DA). The study also focused on one of glare measurements which is Daylight Glare Probability (DGP) [8].

\subsection{Spatial daylight autonomy (sDA)}

sDA is a metric that describes the annual sufficiency of ambient daylight levels in interior environments. It is defined as "the percent of an analysis area that meets a minimum daylight illuminance level for a specified fraction of the operating hours per year" [10].

\subsection{Annual sunlight exposure (ASE)}

ASE is a metric that describes the potential for visual discomfort in interior work environments. It is defined as "the percent of an analysis area that exceeds a specified direct sunlight illuminance level more than a specified number of hours per year". ASE should be considered as a relative value, where a smaller sunlit area specified by the ASE calculation is understood to be preferable and progressively larger areas are more worrisome [10].

\subsection{Daylight availability (DA)}

According to Reinhart et al. (2011) [11], DA is represented and evaluated by a merge of three criteria which are: day-lit, partially day-lit and over-lit areas as follows:

- The day-lit areas: The areas that receive target illuminance at least half the time of occupancy hours.

- The partially day-lit areas: The areas below the target illuminance.

- The over-lit areas: The areas with an oversupply of daylight (10 times greater than target illuminance) are reached for at least $5 \%$ of the working year.

\subsection{Daylight glare probability (DGP)}

Wienold et al. (2006) presented a simplified method which is Daylight Glare Probability (DGP). DGP is used to evaluate the visual comfort and glare aspects. This method represents the probability that a person is disturbed by glare. In this method glare is divided into four categories: intolerable glare (DGP $\geq 45 \%$ ), disturbing glare (45\%> DGP $\geq 40 \%$ ), perceptible glare ( $40 \%>$ DGP $\geq 35 \%)$, and imperceptible glare (DGP <35\%) [18].

As a result of the above, the analysis in this research was carried out on two phases. The first phase focused on the analysis of the "Base Case" through studying the existing DA, sDA, ASE and DGP using dynamic Climate Based Daylighting Metrics (CBDM). On the other hand, the second phase focused on the analysis of the proposed solutions through studying the DA, sDA, ASE and DGP for two alternatives.

\section{Explanation and analysis of the simulation study}

The analysis period was determined by the chosen design studio utilization hours starting from 8:00 AM until 6:00 PM all year round as the design studios are used during the summer courses of the Credit Hours Engineering Program (CHEP). The working plane was taken $90 \mathrm{cms}$ above the finish floor level. The sensors grid plane contained 1330 measuring points with a grid of $0.6 \mathrm{~m} \times 0.6 \mathrm{~m}$. 


\subsection{Base case results}

Simulations for the Base Case were carried-out to evaluate the DA, sDA, ASE \& DGP and the results were as follows:

\subsubsection{DA, sDA \& ASE results}

Figure (6) illustrates the results of the DA, sDA \& ASE for the Base Case. Although the sDA shows that the investigated space is $100 \%$ "daylit", the DA shows that the space is $100 \%$ "overlit". In the meantime, the ASE was $100 \%$ which means that the investigated space was found to be exposed to more than 1000 lux of direct sunlight for more than 250 hours per year. According to IES-The Daylight Metrics Committee (2012), daylight spaces that were predicted to have more than $10 \% \mathrm{ASE}_{1000,250 \mathrm{~h}}$ were judged to have unsatisfactory visual comfort. Consequently, the DGP was investigated.
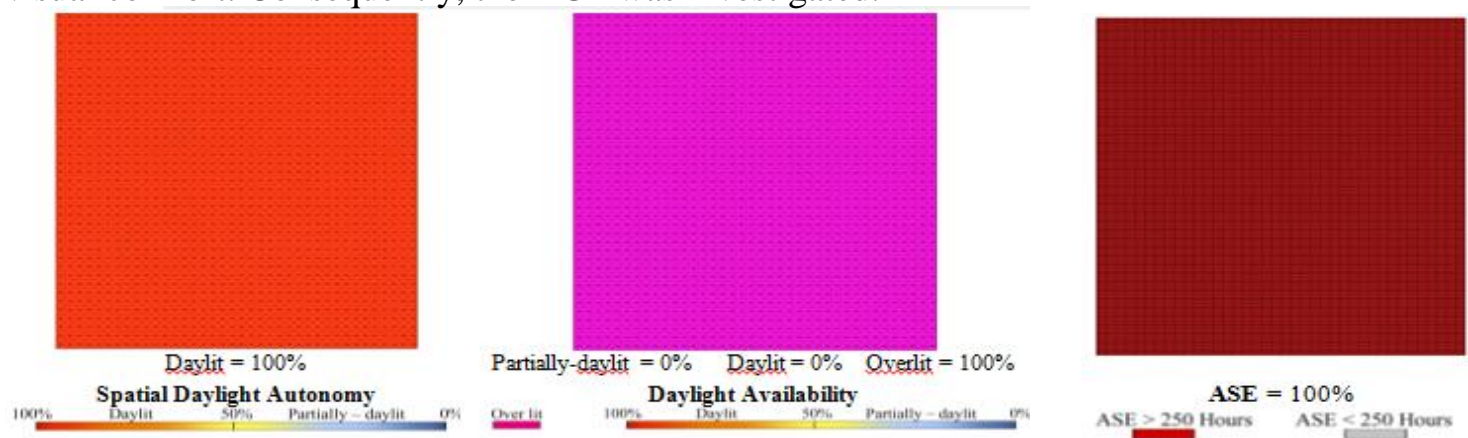

Fig. 6. DA, sDA \& ASE Results for the "Base Case".

\subsubsection{Glare results}

The DGP investigation for the "Base Case" was carried-out on two steps. First, the glare phenomena were investigated during the summer and winter solstice. The glare was investigated at 9:00 am, 12:00pm, and 3:00pm. Then the annual DGP was examined. Figure (7) compares the results for glare at the beginning of the summer (21/6) and winter (21/12).

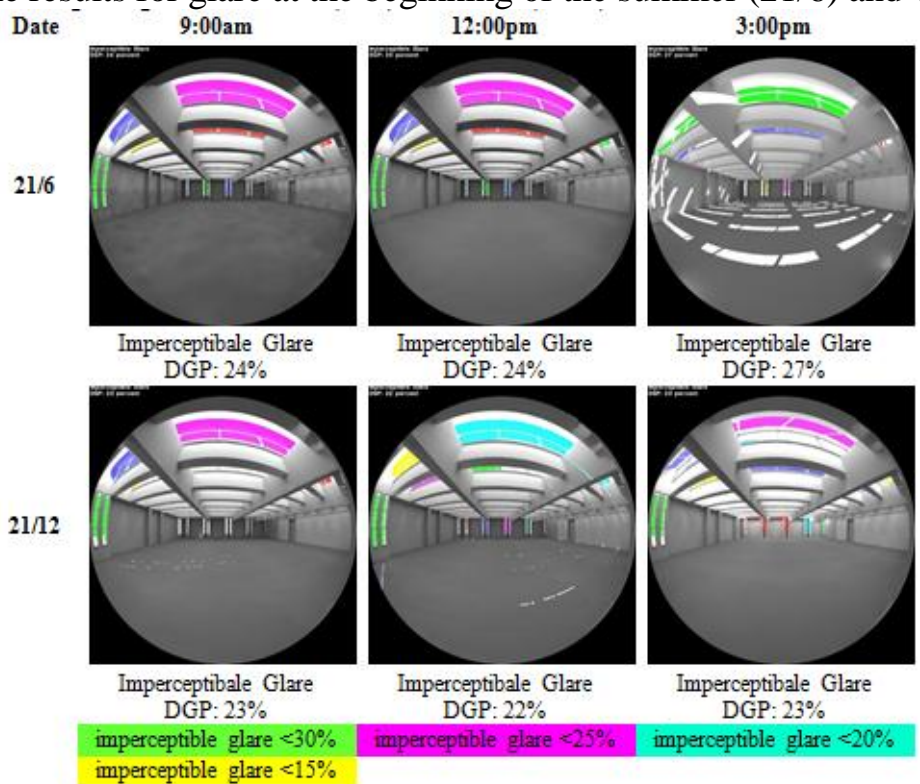

Fig. 7. DGP results for the "Base Case" during the summer and winter solstice showing the presence of imperceptible glare. 
The DGP results for the "Base Case" ranged between 24\% and 27\% during the summer solstice and between $22 \%$ and $23 \%$ during the winter solstice. According to the simplified method presented by Wienold et al. (2006) to evaluate the glare probability, the aforementioned results are satisfactory as it can be categorized as imperceptible glare (DGP <35\%).

In the meantime, Figure (8) shows the results for annual DGP of the "Base Case". While examining the annual DGP, it was found that intolerable glare occurred during the whole year except for October and November. The glare occurred starting from 2:00pm till 5:00pm. Some months during the year showed minor intolerable glare (January, February, March, April, September and December). In May, June, July and August the intolerable glare daily between 3:00pm and 5:00pm. This is particularly important as during May and June, the drawing hall is used on a daily basis as a venue for final examinations and usually the examinations end at 4:30pm.

\subsubsection{Proposed techniques}

In order to enhance the daylighting performance of the sawtooth openings, louvers were proposed to control daylighting and the associated glare. Two different positions for the louvers were investigated as shown in Figure (9). The first proposal was placing the louvers horizontally outside the sawtooth openings (externally). The second proposal was locating the louvers vertically inside the space in-between every two consecutive sawtooth openings. Simulations for both positions were carried-out to evaluate the DA, sDA, ASE \& DGP after implementing the proposed solutions.

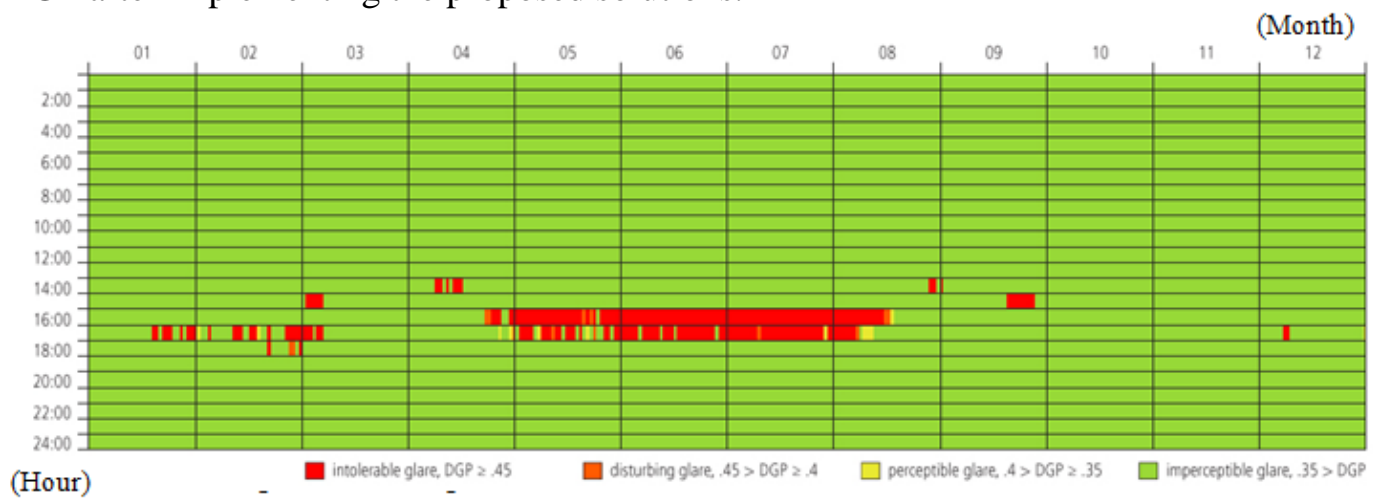

Fig. 8. Annual DGP of the "Base Case" showing the occurrence of glare during the year mostly in May, June, July and Mid-August between 3:00pm and 5:00pm. The vertical axis in the figure represents the daily hours and the horizontal axis represents the months of the year.

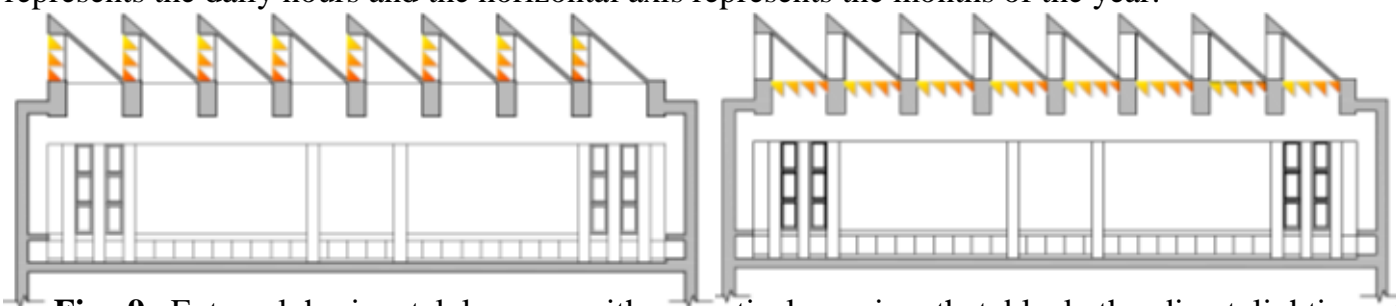

Fig. 9. External horizontal louvers with a vertical spacing that block the direct lighting at 45 degrees and $50 \mathrm{~cm}$ wide (above left) versus internal vertical louvers with a horizontal spacing that block the direct lighting at 45 degrees and $50 \mathrm{~cm}$ deep (above right).

\subsubsection{External horizontal louvers}

Figure (10) illustrates the results of the DA, sDA \& ASE when using external horizontal louvers for sun control. After implementing the proposed horizontal louvers, the sDA shows 
that the space became $82.3 \%$ "Daylit" and that 17.7\% "Partially-daylit". As for the DA, the investigated space became 32.4\% "Daylit", 17.7\% "Parially-daylit", and the "Overlit" area dropped from $100 \%$ to $49.9 \%$. In the meantime, the ASE dropped from $100 \%$ to $5.7 \%$. According to IES-The Daylight Metrics Committee (2012), daylit spaces that were predicted to have less than $10 \% \mathrm{ASE}_{1000,250 \mathrm{~h}}$ were judged to have satisfactory visual comfort.

According to IES acceptance criteria, the sDA achieved (sDA>75\%) was favorable, the ASE $(3 \%<\mathrm{ASE}<7 \%)$ was neutral and the DA (DA> 50\%) was accepted.

The DGP results for the "Base Case" were satisfactory and categorized as imperceptible glare (DGP $<35 \%$ ). However the annual DGP of the "Base Case" showed intolerable glare that occurred during the whole year except for October and November. After examining the annual DGP for the drawing hall after implementing the external horizontal louvers, it was noticed that the intolerable glare was reduced during May, June, July and August as shown in Figure (11).

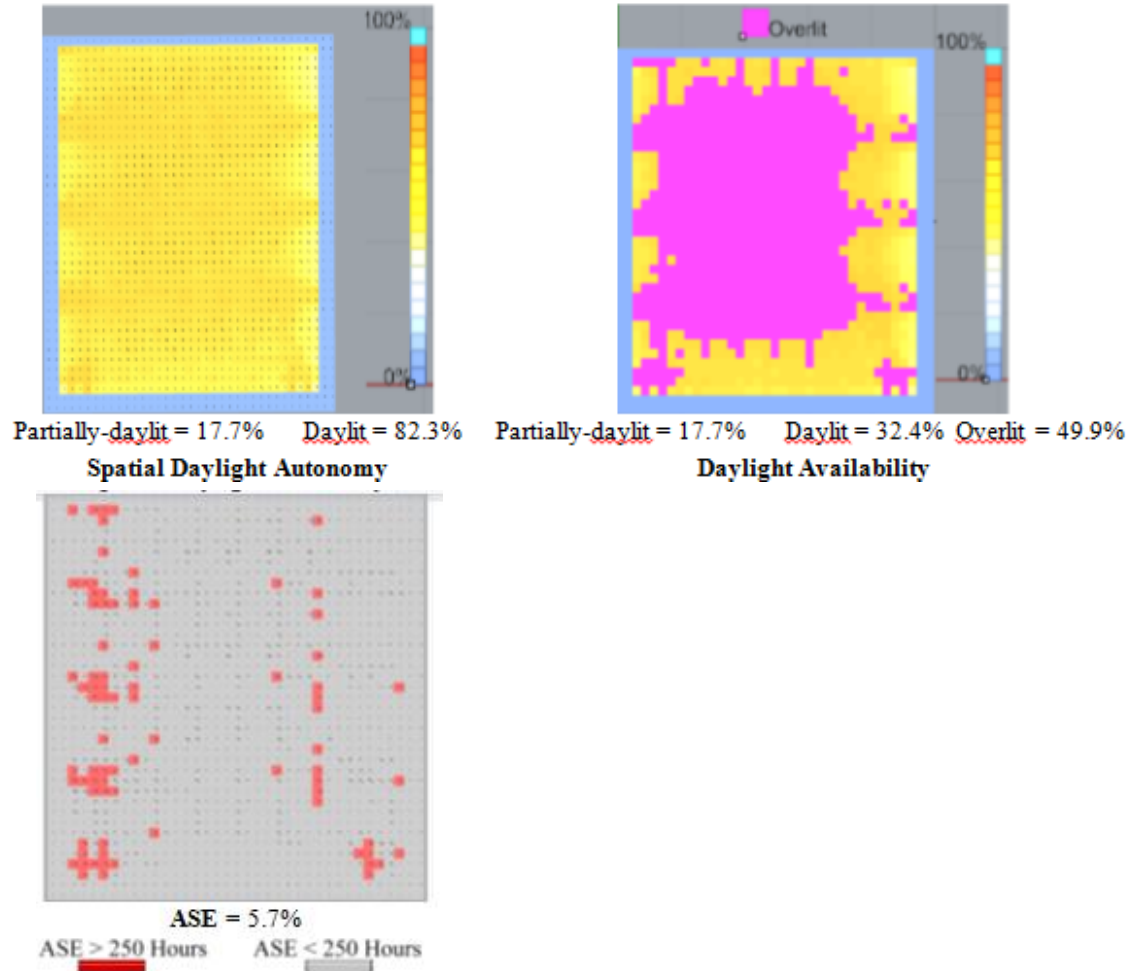

Fig. 10. DA, sDA \& ASE Results when using external horizontal louvers.

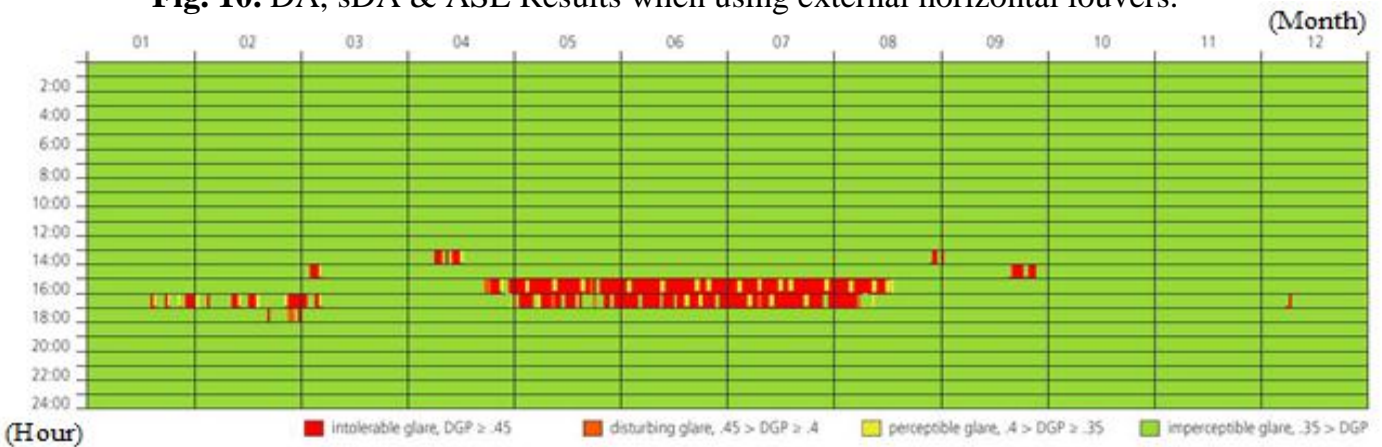

Fig. 11. Annual DGP after adding the external horizontal louvers showing the reduction of glare during May and August. 


\subsubsection{Internal vertical louvers}

Figure (12) illustrates the results of the DA, sDA \& ASE when using internal vertical louvers for sun control. After implementing the proposed horizontal louvers, the sDA shows that the space became 76.7\% "Daylit" and that 23.3\% "Partially-daylit". As for the DA, the investigated space became 31.1\% "Daylit", 23.3\% "Parially-daylit", and the "Overlit" area dropped from $100 \%$ to $45.6 \%$. In the meantime, the ASE dropped from $100 \%$ to $4.6 \%$. According to IES-The Daylight Metrics Committee (2012), daylit spaces that were predicted to have less than $10 \% \mathrm{ASE}_{1000,250 \mathrm{~h}}$ were judged to have satisfactory visual comfort.

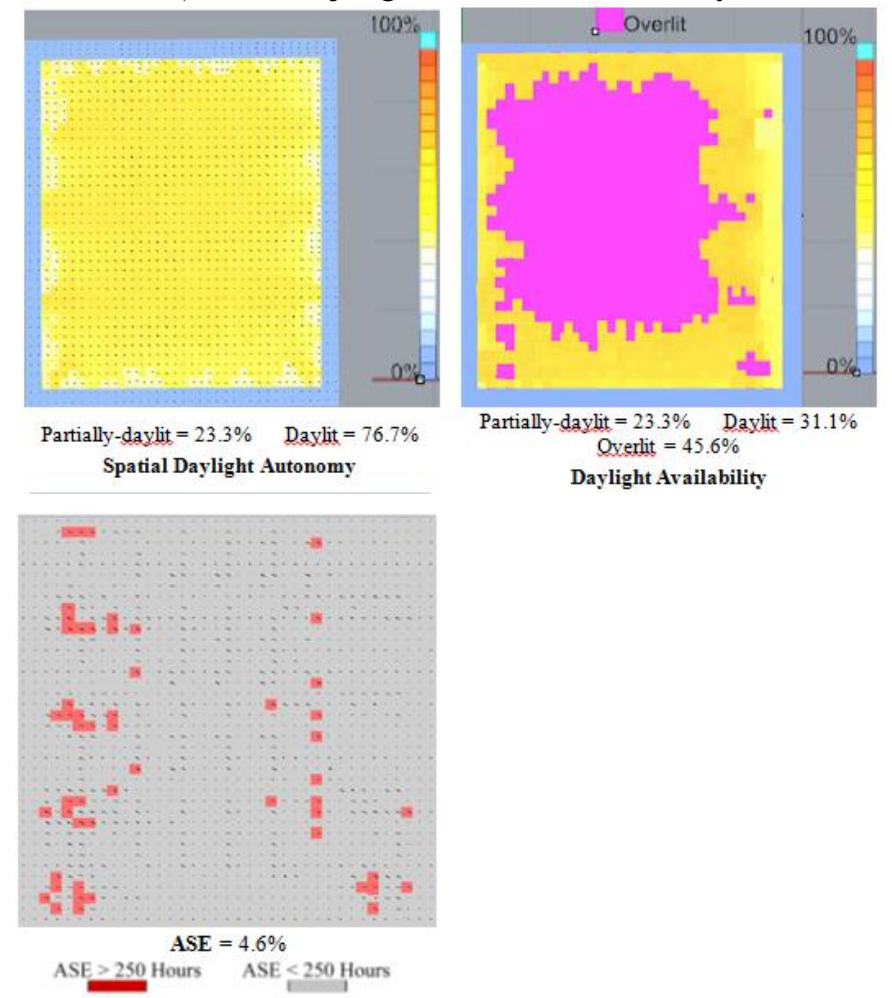

Fig. 12. DA, sDA \& ASE Results when using internal vertical louvers.

According to IES acceptance criteria, the sDA achieved (sDA>75\%) was favorable, the ASE $(3 \%<\mathrm{ASE}<7 \%)$ was neutral but the DA achieved (DA>50\%) was not accepted.

After examining the annual DGP for the drawing hall after implementing the internal vertical louvers, it was noticed that the intolerable glare was reduced during May, June, July and Mid-August which reflects a better performance than the external horizontal louvers as shown in Figure (13).

\section{Results of the simulation study}

This paper investigated the utilization of one technique, namely using louvers with different positions, for the enhancement of the daylight performance in hot arid climate. Table (2) compares the results of the sDA, DA, ASE, and Annual DGP for the "Base Case" results, the external louvers results and the internal louvers results. 


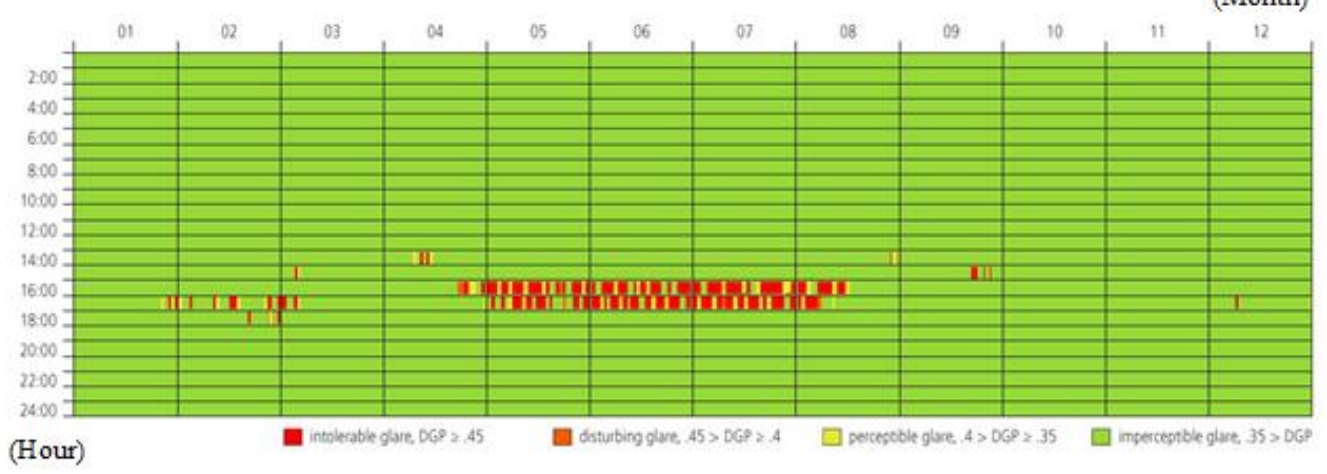

Fig. 13. Annual DGP after adding the internal vertical louvers showing the reduction of glare during the whole year.

Table. 2.

Comparison of the sDA, DA, ASE, and Annual DGP results for the "Base Case" versus the proposed solutions.

\begin{tabular}{|c|c|c|c|c|c|c|c|}
\hline & \multicolumn{2}{|c|}{$\begin{array}{c}\text { Spatial Daylight } \\
\text { Autonomy (sDA) }\end{array}$} & \multicolumn{3}{|c|}{ Daylight Availability (DA) } & \multirow{2}{*}{$\begin{array}{c}\text { Annual } \\
\text { Sunlight } \\
\text { Exposure } \\
\text { (ASE) }\end{array}$} & \multirow{2}{*}{$\begin{array}{c}\text { Annual DGP } \\
\text { May / June / July / } \\
\text { Mid-August } \\
\text { between 3:00pm } \\
\text { \& 5:00pm }\end{array}$} \\
\hline & $\begin{array}{c}\text { Partially- } \\
\text { daylit }\end{array}$ & Daylit & $\begin{array}{c}\text { Partially- } \\
\text { daylit }\end{array}$ & Daylit & Overlit & & \\
\hline $\begin{array}{l}\text { Base } \\
\text { Case }\end{array}$ & $0 \%$ & $100 \%$ & $0 \%$ & $0 \%$ & $100 \%$ & $100 \%$ & Intolerable Glare \\
\hline $\begin{array}{l}\text { External } \\
\text { Louvers }\end{array}$ & $17.7 \%$ & $82.3 \%$ & $17.7 \%$ & $32.4 \%$ & $49.9 \%$ & $5.7 \%$ & Disturbing Glare \\
\hline $\begin{array}{l}\text { Internal } \\
\text { Louvers }\end{array}$ & $23.3 \%$ & $76.7 \%$ & $23.3 \%$ & $31.1 \%$ & $45.6 \%$ & $4.6 \%$ & $\begin{array}{c}\text { Disturbing \& } \\
\text { Perceptible Glare }\end{array}$ \\
\hline
\end{tabular}

The obtained results of the sDA show clearly that the external louvers reduced the "Daylit" areas to $82.3 \%$ and increased the "Partially-daylit" areas by $17.7 \%$. Meanwhile, the internal louvers reduced the "Daylit" areas to $76.7 \%$ and increased the "Partiallydaylit" areas by $23.3 \%$. According to the IES acceptance criteria for sDA, both results are accepted and considered "Favorable".

As for the DA, the "Overlit" area dropped from $100 \%$ in the "Base Case" to $49.9 \%$ in case of using "External Louvers" and $45.6 \%$ in case of using "Internal Louvers". The DA is accepted in case of the "External Louvers" but unacceptable in case of the "Internal Louvers".

As for the ASE results, and according to the IES acceptance criteria for ASE, the "Base Case" was considered "Unsatisfactory Visual Comfort". However, both proposed solutions resulted in 3\%<ASE<7\% which is considered as "Neutral" visual comfort.

By comparing the results, both proposed solutions achieved near performance in providing acceptable levels of sDA and ASE. However, the external horizontal louvers achieved better performance and lower DGP when compared to the internal vertical louvers in providing an acceptable level of DA in case of using it in hot arid climate. 


\section{Discussion}

The findings of this research highlighted the importance of using simulation tools in the design process of daylighting in general and toplighting techniques in particular and its importance in evaluating the proposed techniques in case of retrofitting additional louvers. Also, it can be utilized to evaluate the performance of various daylight control techniques that might be needed to enhance the performance. As each technique performs differently according to its parameters, considering and testing these parameters makes a real difference in the overall performance.

The research showed the promising potential of using computational methods along with simulation tools. It paves the way for more research in the area of building performance and its relation with the design of the building.

\section{Conclusion}

As a conclusion, both proposed solutions achieved near performance in providing acceptable levels of sDA and ASE. However, the external horizontal louvers achieved better performance when compared to the internal vertical louvers in providing an acceptable level of DA in case of using it in hot arid climate.

As final note, this research demonstrated the usefulness of retrofitting louvers as solar screens in toplit spaces to enhance the daylight performance under clear sunny skies almost all year round. However, it is important to balance this improvement with glare analysis to assure visual comfort at the same time. Generalization of these conclusions would be more reliable if they get supported by evidence of physical modeling.

\section{Recommendations}

The paper investigated the effect of retrofitting of louvers in two different positions, external and internal, on the daylighting performance of toplit spaces. Additional research examining the louvers parameters (material reflectance, dimensions, angle, and spacing) is advised. Future research that links the optimum toplighting glazing area with the space area is recommended.

Further research investigating the use of dynamic daylight control techniques for more adaptive solutions and comparing the feasibility of dynamic versus fixed techniques may give a clearer view for the designer to achieve a better visual environment in toplit educational spaces with even daylighting distribution.

Moreover, additional research can be carried-out to correlate toplighting with the following aspects: energy consumption, thermal comfort, natural ventilation, and life cycle cost.

\section{REFERENCES}

[1] Abdelatia, B., Marenne, C., Semidor, C., (2010), "Daylighting Strategy for Sustainable Schools: Case Study of Prototype Classrooms in Libya", Journal of Sustainable Development (Published by Canadian Center of Science and Education), Vol. 3, No. 3, 60-67.

[2] Alrubaih, M., Zain, M., Alghoul, M., Ibrahim, M. (2013), "Research and Development on Aspects of Daylighting Fundamentals", Renewable and Sustainable Energy Reviews (21) 494-505.

[3] Al-Sallal, K. (2007), "Testing Glare in Universal Space Design Studios in Al-Ain, UAE Desert Climate and Proposed Improvements”, Renewable Energy (32), 1033-1044. 
[4] Bellia, L., Cesarano, A., Iuliano, G., Spada, G. (2008), "Daylight Glare: A Review of Discomfort Indexes". In: Proceedings of CIE 2010 Lighting Quality, visual quality and energy efficiency in indoor lighting: Today for Tomorrow, Rome, Italy.

[5] Bellia, L., Pedace, A., and Barbato, G. (2013), "Lighting in Educational Environments: An Example of a Complete Analysis of the Effects of Daylight and Electric Light on Occupants", Building and Environment (68), 50-65.

[6] DIVA FOR RHINO, [URL: http://diva4rhino.com/ ], Last Accessed: January 2017

[7] Dubois, M., Gentile, N., Amorim, C., Osterhaus, C., Stoffer, S., Jakobiak, R., GeislerMoroder, D., Matusiak, B., Onarheim, F., and Tetri, E., (2016), "Performance evaluation of lighting and daylighting retrofits: results from IEA SHC task 50", SHC 2015, International Conference on Solar Heating and Cooling for Buildings and Industry, Energy Procedia (91), $926-937$.

[8] Galatioto, A., Beccali, M., (2016), "Aspects and Issues of Daylighting Assessment: A Review Study", Renewable and Sustainable Energy Reviews (66), 852-860.

[9] Hraska, J. (2015), “Chronobiological Aspects of Green Buildings Daylighting”, Renewable Energy (73) 109-114

[10] Illuminating Engineering Society (IES); The Daylight Metrics Committee, (2012): "Approved Method: IES Spatial Daylight Autonomy (sDA) and Annual Sunlight Exposure (ASE)", p.2.

[11] Reinhart,C.; Mardaljevic,J.; Rogers,Z. (2006): "Dynamic Daylight Performance Metrics for Sustainable Building Design", Leukos (The Journal of Illuminating Engineering Society of North America), V.3, no.1, p.1.

[12] Sabry, H., Sherif, A., Gad Elhak, M., Rakha, T., (2012). External Perforated Solar Screen Parameters and Configurations: Daylighting Performance of Screen Axial Rotation and Opening Proportion in Residential Desert Buildings. In Proceedings of the International Conference on Computing in Civil and Building Engineering, 27 - 29 June 2012, Moscow, Russia.

[13] Sabry, H., Sherif, A., Gad Elhak, M., (2012), "Utilization of Combined Daylighting Techniques for Enhancement of Natural Lighting Distribution in Clear-Sky Residential Desert Buildings", In Proceedings of PLEA2012 - 28th Conference, "Opportunities, Limits \& Needs Towards an environmentally responsible architecture", 7-9 November 2012, Lima, Perú.

[14] Sherif, A., Sabry, H., Wagdy, A., Mashaly, I., and Arafa, R. (2016), "Shaping the Slats of Hospital Patient Room Window Blinds for Daylighting and External View under Desert Clear Skies", Solar Energy (133), 1-13.

[15] Skarning, G., Hviid, C., and Svendsen, S. (2017), "The Effect of Dynamic Solar Shading on Energy, Daylighting and Thermal Comfort in a nearly Zero-Energy Loft Room in Rome and Copenhagen", Energy and Buildings (135), 302-311.

[16] The Daylight Site, Daylighting Simulation Tools, [URL: http://thedaylightsite.com/library3/links/simulation-tools-2/], Last Accessed: January 2017

[17] Tzempelikosa, A., (2017), Editorial, "Advances on Daylighting and Visual Comfort Research", Building and Environment (113), 1-4.

[18] Wienold, J., Christoffersen, J., (2006): "Evaluation Methods and Development of a New Glare Prediction Model for Daylight Environments with the Use of CCD Cameras", P.743-757. 


\section{تحسين أداء الإضاءة الطبيعية فى صالات الرسم المضاءة بفتحات علوية بإستخدام

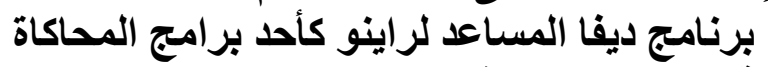

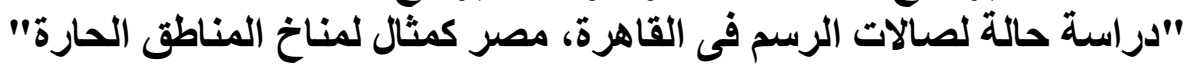

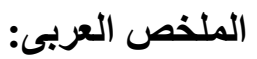

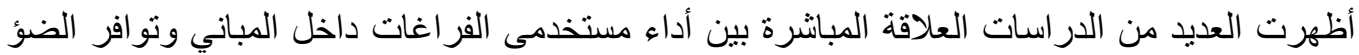

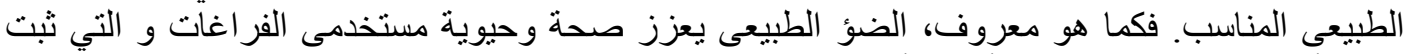

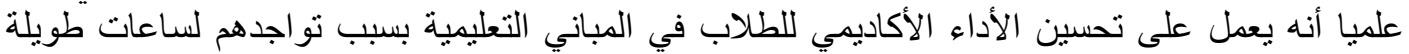

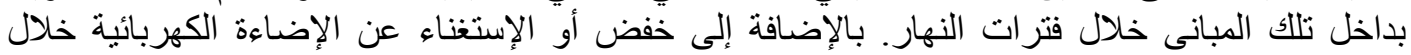
ساعات النهار ، الضؤ الطييعى يساعد على خلق بيئة محفزة بصريا وبيئة أكثر إنتاجية لمستخدمى الفر الاغات.

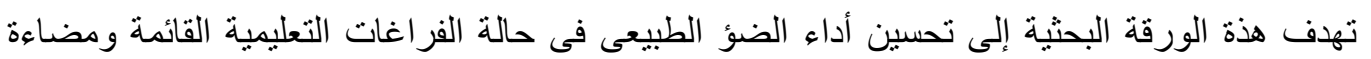

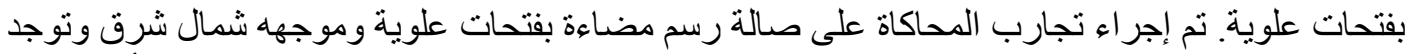

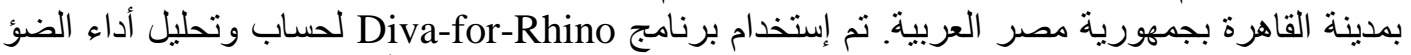

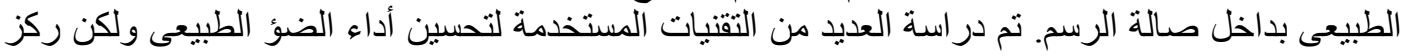

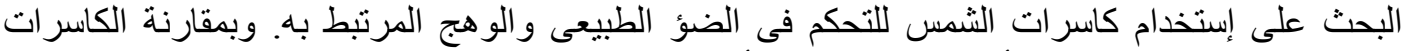

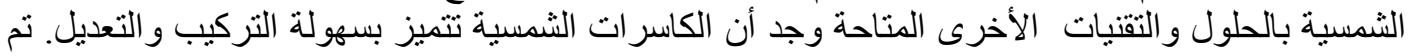

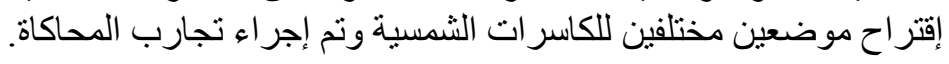

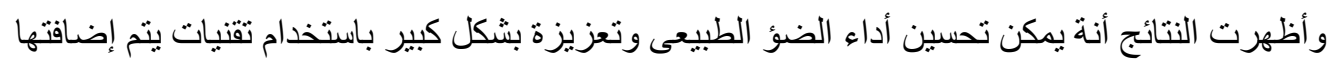

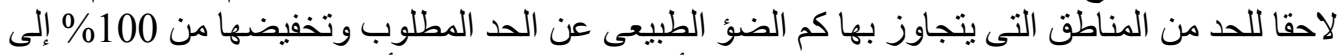

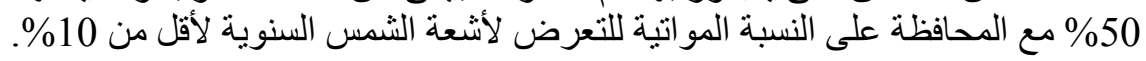

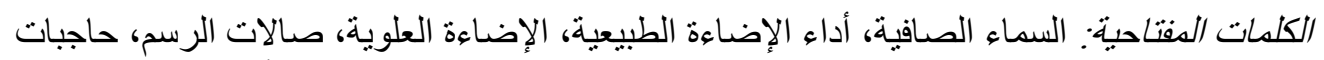

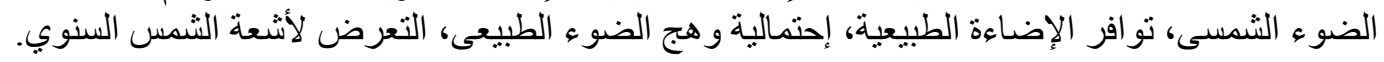

